\title{
An Assessment of Life Satisfaction among Women
}

\author{
Muzamil Jan* and Tasia Masood \\ Extension and Communication, Institute of Home Science, University of Kashmir, \\ Jamia Masjid, Wahab Sahab, Srinagar 190 002, Jammu and Kashmir, India \\ * Mobile: 9419747179,*E-mail: muzamil_research@mail.com
}

KEYWORDS Women. Life Satisfaction. Socio-Economic Profile. Career. Social. Familial and Personal Life Satisfaction.

\begin{abstract}
Life satisfaction is widely considered to be central aspect of human welfare. Life satisfaction is not merely a judgment about one's life. For it is widely thought to involve affirming, endorsing, appreciating or being pleased with one's life. The present study is an attempt to evaluate life satisfaction among women and to analyze the influence of socio-personal characteristics of women with their life satisfaction. To fulfill these objectives, 120 women were selected from Jammu and Kashmir, through multi-stage sampling method, using questionnaire and scale regarding "Life Satisfaction among Women", constructed.The data was analyzed, computing percentage, chisquare value, ANOVA, Karl Pearson's co-relation and degree of freedom. The study depicts that women have average level of life satisfaction at all age levels. It is found that with an increase in age, the overall life satisfaction decreases; whereas, with an increase in personal income, the over all life satisfaction increases. Moreover, with an increase in family income, the over all life satisfaction of women also increases. The study paves the way for further research.
\end{abstract}

\section{INTRODUCTION}

Life satisfaction is defined as having a favourable attitude towards one's life as a whole. The vast majority of studies investigating life satisfaction have been survey based. The current paper measures life satisfaction with good reliability and validity. Although most research on life satisfaction has not been directly focused on the experiences of women, few studies have investigated the unique predictors of life satisfaction for women. For example, several studies have demonstrated that the greater the gender equality within a culture (i.e., freedom to make reproductive choices, equal pay, equal value under the law, equal opportunity to education and achievement), the greater reported life satisfaction (Sousa and Lyubomirsky 2000).

\section{Review of Literature}

Currently, the literature suggests that personality play a significant role in whether a woman will judge her life to be satisfying. However, proximal environmental factors (e.g., recent life events) can influence life satisfaction judgments in the short term. Both nature and nurture (i.e., personality and environment) appear to be influential in determining life satisfaction, and to discount one explanation in favour of the other, would not be empirically or theoretically productive. (Beutell 2006.)
Chipper field and Havens (2001) conducted a study to examine life satisfaction among individuals who had undergone a transition in marital status and those whose marital status remained stable over 7-year period. Among those individuals whose marital status remained stable over the 7 years, women's life satisfaction declined and men's remained constant. Among those who experienced a transition - in particular, the loss of spouse - a decline in life satisfaction was found for both men and women decline being more predominant for men. In addition, men's life satisfaction increased over the 7 years period if they gained a spouse, where as the same was not true for women. Generally, these findings imply that the relationship between marital status transitions or stability differs for men and women.

In a study of Sousa and Lyubomirsky (2001) women's hostility towards other women were inversely associated with their life satisfaction. That is, women who harbored hostile feelings toward other women were less likely to be satisfied with their own lives. The study suggested that people's perceptions of their life satisfaction are in part due to comparisons that they make between what they have, what they want, what they used to have, and what others have. Thus, hostility toward other women may be a consequence of unfavorable social comparisons. That is, the recognition that another woman is 
clearly better off may be related to dissatisfaction with one's own life.

Saundra and Hughey (2003) conducted a study on life satisfaction. In this study, 147 African American women from six states were asked to complete the Adult Life Satisfaction Scale and the Black Women's Spirituality/Religiosity Measure (BWSRM). Although no significant difference was found among the ratings of life satisfaction and spirituality with respect to age or educational level, the women reported higher levels of religiosity than spirituality, which correlates significantly with life satisfaction. Spirituality contributed to the life satisfaction of African-American women at midlife regardless of age, income, or education.

Bettencourt and Molix (2003) conducted a study to examine the ways in which satisfaction with health care may be associated with the lives of rural women. One hundred thirty one rural women between the ages of 45 and 70 years completed measures of community esteem, life satisfaction, satisfaction with health care, health status, and mood. The results showed that rural women's satisfaction with their health care was associated with the extent to which they hold their community esteem and their degree of life satisfaction. Moreover, women who had poor health were less satisfied with the available health care than were healthier women.

Shichman and Cooper (2004) investigated the relationship between life satisfaction and sexrole concept. Two hundred and seventeen respondents completed a two-part questionnaire, which consisted of the life satisfaction survey. General satisfaction with life was found to be a function of the level of satisfaction derived from various aspects of life, particularly aspects chosen as the most important. Consistent with previous studies, general satisfaction with life was positively associated with education level, income level, and being married. Psychologically masculine people choose an important and enjoy more instrumental aspects of life; psychologically feminine people choose an important and enjoy more the Socio emotional aspects of life; psychologically androgynous people choose an important and enjoy more both the instrumental and Socio emotional aspects of life.

Kousha and Moheen (2004) explored life satisfaction among unmarried Iranian women in urban areas. Data was analyzed from a sample of
335 women of which $61 \%$ were married and $39 \%$ were unmarried (i.e., single, divorced or widows). A series of path analysis and cross tabulations suggest that for married women life satisfaction is directly linked to their satisfaction with marriage, employment and their leisure experiences. There is an inverse relationship between satisfaction and the women's activity. However, for unmarried women, satisfaction is affected by their leisure experiences and educational level. The study suggests that any effort to reduce or increase the educational, employment, or leisure activities or women while directly affect women's general satisfaction and therefore affect Iranian society as a whole.

Borg et al. (2006) investigated life satisfaction and its relation to living conditions, overall health, self-care capacity. A sub sample of 522 persons was selected from a randomly selected cross-sectional survey using a modified form of the Older Americans' Resources Schedule and Life Satisfaction Index. Life satisfaction in older people with reduced self-care capacity is determined by several factors, with social, physical, mental and financial aspects probably interacting with each other; especially feeling lonely, degree of self-care capacity, poor overall health, feeling worried and poor financial resources in relation to needs. These factors need to be considered in the care of these people to preserve or improve their life satisfaction.

Young (2006) conducted a study to explore the relationship between social support and life satisfaction for people with long-term mental illness. Research sample included 146 subjects, coming from two large residential homes in Hong Kong. Results show that different sources of social support have different effects on individual's life satisfaction Emotional and instrumental supports from staff and friend have different predictive power and importance on individual's life satisfaction. These findings suggest that strengthening staff and friend's support could improve life satisfaction for people with long-term mental illness.

\section{Objectives of Study}

The study was undertaken to see the overall life satisfaction among women with the following objectives:

1. To evaluate life satisfaction among women. 
2. To assess the extent of life satisfaction among women as per their socio-economic characteristics

3. To observe the various aspects of life satisfaction among women in their personal, familial, social and professional life

\section{Rationale of Study}

The vast majority of research on life satisfaction investigates the extent to which various demographic variables predict life satisfaction. However, because researches are not able to perform true experiments by randomly assigning participates to demographic groups (e.g., gender, income, age), all of this research has necessarily been correctional. Much of the work has focused on the "objective" determinates of life satisfaction, that is, the extent to which satisfaction is related to the environment, both imposed (e.g., culture) and relatively controllable (e.g., income, occupation, education, marriage), as well as to specific aspects of persons (e.g., gender, age). Women comprise nearly half of the national population of any country. Hence the development of any country is inseparably linked with the status of development of women. It, therefore, becomes the role and responsibility of scholars, educationists, socialists, media and voluntary agencies also to act as catalyst, an agent of change to cause stir in the minds of men and storm in the minds of women. The women of present age exhibit their abilities in every field. The present study is an attempt to evaluate the life satisfaction among women. Besides this, the present study tries to enlighten the various components of life satisfaction i.e., personal satisfaction, career satisfaction, social satisfaction and familial satisfaction.

\section{MATERIALS AND METHODS}

For the present study, the sample was derived from both rural and urban areas, which comprised of 120 women from Jammu and Kashmir, India. Primary data was collected in 2007 and was distributed among working, non-working, rural and urban women. Multi-stage sampling method was used. In addition to structured questionnaire, life satisfaction scale was used to collect data which was constructed by Singh and Joseph (1971). The scale regarding life satisfaction comprised 38 items under 5 responses i.e., never, seldom, sometimes, often and always were utilized. Never was coded as 1 , seldom as 2 , sometimes as 3 , often as 4 and always was coded as 5 . The validity of the scale was tested through reliability test and was found reliable by 87 per cent. The statistics applied on the data comprises, percentage, chi-square value, degree of freedom, levels of significance, ANOVA and correlation. The levels of significance were obtained at highly significant ( $\mathrm{p}$-value $<0.01$ ) significant ( $\mathrm{p}$-value $<0.05$ ) and insignificant ( $p$-value $>0.05$ ).

Age was divided in 3 levels i.e. low age group, middle age group and high age group. Low age group comprised the women respondents who were up to the age of 25 years and middle age group of 25-35 years. Similarly high age group comprised women who were more than 35 years.

Personal Income of women was divided in 4 levels i.e. nil, low, middle and high income. Nil income group comprised women respondents who had no personal income; low-income group comprised Rs 2500/- month; middle-income group comprised personal incomes of Rs 25005000/- month. Similarly, high-income group comprised more than Rs 5000/- month.

Family Income of women was divided in 3 levels i.e. low, middle, and high-income group. Low-income group comprised of women respondents whose family incomes were up to Rs 4000 /month, middle income group comprised between Rs 4000-8000/- months and high-income comprised more than Rs 8000/- month.

The total scores of life satisfaction resolved round 35 to 175 . The low level of general life satisfaction comprised the scores up to 50 per cent i.e., up to 88 score. Average level of life satisfaction comprised the scores up to 50-70 per cent i.e., >, is between 89-123 scores. Similarly, high level of life satisfaction comprised the scores $>70$ per cent i.e., > 124 score.

In addition to general assessment of life satisfaction, the scale was divided in 4 categories i.e., career satisfaction, social satisfaction, familial satisfaction and personal satisfaction.

Career satisfaction comprised scores from 1050. Low level of career satisfaction comprised scores up to 50 per cent (scoring from 10-25). Medium level of career satisfaction comprise scores from $50-70$ percent (i.e., scoring from 26 -35 ) and high levels of career satisfaction comprises more than 70 percent (i.e., scoring from 36 -50 ). 
Social satisfaction comprised the scores from $5-25$. Low level of social satisfaction included scores up to 50 per cent (scoring 5 - 12). Medium level of social satisfaction encompasses scores up to $50-70$ per cent (scoring 13 - 17) and high level of social satisfaction included more than 70 per cent score (i.e., scoring 18 - 25).

Familial satisfaction included the scores from 4-20. The lower level of it comprising 50 per cent i.e., between 4-10 scores; medium level scored 11-14 for 50-70 per cent and high level of it scored 15-20 i.e., more than 70 per cent.

Personal satisfaction comprised the minimum score of 16 and maximum scores of 80 . The levels of personal satisfaction included 16-40 scored (up to 50 per cent); the medium level scored 4056 (50-70 per cent) and high level of personal satisfaction scored $57-80$ (more than 70 per cent).

\section{RESULTS AND DISCUSSION}

Table 1 observes the life satisfaction among women as per their age. It is found that low level of satisfaction in career has been found mostly among high level of age group by 75.00 per cent. Average level of satisfaction in career is found mostly among women at high level of age group by 37.93 per cent; whereas, high level of satisfaction in career is found mostly among women at average level of age group by 43.1 per cent. Such differences between career satisfaction and age of women is found insignificant (p-value $>0.05$ ) with $\chi^{2}$ value of 8.41 per cent at 4 degree of freedom. Thus, high-level career satisfaction is found among women at average level of age group and low level of career satisfaction is found among women at high age group.

Low level of social satisfaction has been found mostly among women at high level of age group by 60 per cent. Average level of social satisfaction is also found among women at high level of age group by 40.00 per cent; whereas, high level of social satisfaction is found mostly among women at average level of age group by 43.75 per cent. Such differences between social satisfaction and age is found insignificant ( $p$ -

Table 1: Life Satisfaction among women as per their age $(\mathbf{n}=120)$

\begin{tabular}{|c|c|c|c|c|c|c|c|c|c|}
\hline \multirow[t]{3}{*}{ Life Satisfaction } & \multicolumn{8}{|c|}{ Age } & \multirow[t]{3}{*}{$\chi^{2}$ analysis } \\
\hline & \multicolumn{2}{|c|}{ Low } & \multicolumn{2}{|c|}{ Average } & \multicolumn{2}{|c|}{ High } & \multirow[t]{2}{*}{ Total } & \multirow[t]{2}{*}{$\%$} & \\
\hline & $N$ & $\%$ & $N$ & $\%$ & $N$ & $\%$ & & & \\
\hline \multicolumn{10}{|c|}{ Career Satisfaction } \\
\hline Low & 1 & 25.00 & - & - & 3 & 75.00 & 4 & 100.00 & \multirow{4}{*}{$8.41_{4}^{* * *}$} \\
\hline Average & 15 & 25.86 & 21 & 36.21 & 22 & 37.93 & 58 & 100.00 & \\
\hline High & 21 & 36.21 & 25 & 43.10 & 12 & 20.69 & 58 & 100.00 & \\
\hline Total & 37 & 30.83 & 46 & 38.33 & 37 & 30.83 & 120 & 100.00 & \\
\hline \multicolumn{10}{|c|}{ Social Satisfaction } \\
\hline Low & 1 & 20.00 & 1 & 20.00 & 3 & 60.00 & 5 & 100.00 & \multirow{4}{*}{$53.33_{4}^{* * *}$} \\
\hline Average & 11 & 31.43 & 10 & 28.57 & 14 & 40.00 & 25 & 100.00 & \\
\hline High & 25 & 31.25 & 35 & 43.75 & 20 & 25.00 & 80 & 100.00 & \\
\hline Total & 37 & 30.83 & 46 & 38.33 & 37 & 30.83 & 120 & 100.00 & \\
\hline \multicolumn{10}{|c|}{ Familial Satisfaction } \\
\hline Low & 2 & 50.00 & 1 & 25.00 & 1 & 25.00 & 4 & 100.00 & \multirow{4}{*}{$1.39_{4}^{* * *}$} \\
\hline Average & 12 & 33.33 & 12 & 33.33 & 12 & 33.33 & 36 & 100.00 & \\
\hline High & 23 & 28.75 & 33 & 41.75 & 24 & 30.00 & 80 & 100.00 & \\
\hline Total & 37 & 30.83 & 46 & 38.33 & 37 & 30.83 & 120 & 100.00 & \\
\hline \multicolumn{10}{|c|}{ Personal Satisfaction } \\
\hline Low & - & - & 1 & 33.33 & 2 & 66.67 & 3 & 100.00 & \multirow{4}{*}{$2.41_{4}^{* * *}$} \\
\hline Average & 14 & 31.82 & 16 & 36.36 & 14 & 31.82 & 44 & 100.00 & \\
\hline High & 23 & 31.51 & 29 & 39.73 & 21 & 28.77 & 73 & 100.00 & \\
\hline Total & 37 & 30.83 & 46 & 38.33 & 37 & 30.83 & 120 & 100.00 & \\
\hline \multicolumn{10}{|c|}{ Overall Satisfaction } \\
\hline Low & - & - & - & - & - & - & - & - & \multirow{4}{*}{$4.93_{2}^{* * *}$} \\
\hline Average & 76 & 18.75 & 12 & 37.50 & 14 & 43.75 & 32 & 100.00 & \\
\hline High & 31 & 35.23 & 34 & 38.64 & 23 & 26.14 & 88 & 100.00 & \\
\hline Total & 37 & 30.83 & 46 & 38.33 & 37 & 30.83 & 120 & 100.00 & \\
\hline
\end{tabular}

Row Percentage

$* * *$ p-value $>0.05$ (Insignificant)

Degree of freedom (d.f) in subscripts of $\chi^{2}$-value 
value $>0.05$ ) with $\chi^{2}$ value of 5.33 at 4 degree of freedom Thus, average level of social satisfaction is found among women at low age group, high level of social satisfaction is found among women at average level of age group and low level of social satisfaction is found among women at high age group.

It is studied that low level of familial satisfaction is found among women at low age group i.e., 50.00 per cent. Majority of women possess average level of familial satisfaction. High level of familial satisfaction is found among women at average level of age group. Such differences between familial satisfaction and age is found insignificant ( $p$-value $>0.05$ ) with $\chi^{2}$ value of 1.39 at 4 degree of freedom Thus, low level of familial satisfaction is found among women at low age group, high level of familial satisfaction is found among women at average level of age group and average of familial satisfaction is found among women at high level of age group.

It is observed that low level of personal satisfaction mostly among high level of age group i.e. 66.67 per cent. Average level of personal satisfaction is found mostly among women at average level of age group i.e. 30.36 per cent and high level of personal satisfaction is also found mostly among women at average level of age group. Such differences between personal satisfaction and age is found insignificant ( $\mathrm{p}$-value $>0.05$ ) with $\chi^{2}$ value of 2.41 at 4 degree of freedom. Thus, average level of familial satisfaction is found among women at low age group and high level of personal satisfaction is found among women at high age group.

No women possess low level of overall life satisfaction. Average level of overall life satisfaction is found among women at high age group i.e. 43.75 per cent and high level of overall life satisfaction is found among women at average level of age group i.e. 38.64 per cent. Such differences between overall life satisfaction and age is found insignificant ( $\mathrm{p}$-value $>0.05$ ) with $\chi^{2}$ value of 4.43 at 2 degree of freedom. Thus, high level of overall satisfaction is found among women at low and average level of age group; whereas, average level of overall satisfaction is found among women at high age group. George et al. (1979) indicated the degree to which age moderates the impact of several predictors of life satisfaction. Although the total and direct effects of age are trivial, age is an important moderator of the effects of marital status, income, health and social support upon life satisfaction.

\section{Life Satisfaction among Women as per their Education}

Table 2 observes the life satisfaction among women as per their education. Low level of career satisfaction is found among illiterate women by 75.00 per cent. Average level of career satisfaction is found among educated women by 44.83 per cent and high level of career satisfaction is also found among educated women by 89.66 per cent. Such differences between career satisfaction and education is found insignificant ( $\mathrm{p}$ value $>0.05$ ) with $\chi^{2}$ value of 38.29 at 4 degree of freedom. Thus, low level of career satisfaction is found among illiterate women, average level of career satisfaction is found among literate women and high level of career satisfaction is found among educated women. Herr (1992) examined the emerging trends in counselling, particularly career counselling, in relation to education, career and employment. It deals with the emphasis and with the comprehensive population for whom education, career and employment content may be different, but important. In various settings, school, universities, business and industry and community particularly important are the counselling associated with unemployment, underemployment, career and job change and persons with disabilities.

It is found from table 2 that low level of social satisfaction is found among literate and illiterate women by 40.00 per cent. Average level of social satisfaction is found among educated women by 78.75 per cent. Such differences between social satisfaction and education is found insignificant ( $p$-value $>0.05$ ) with $\chi^{2}$ value of 21.47 at 4 degree of freedom. Findings of Ramber et al. (2005) also indicated support of bachelors level education for individual and social return on investment and they show that adult education might have unintended consequences and influences on social satisfaction.

It is also studied from table 2 that average level of familial satisfaction is among educated women by 50.00 per cent. Such differences between familial satisfaction and education is found insignificant ( $\mathrm{p}$-value $>0.05$ ) with $\chi^{2}$ value of 11.13 at 4 degree of freedom. Low and average level of familial satisfaction is found among literate women and high level of familial satisfaction is among educated women.

It is found that low level of personal satisfaction is found among illiterate women by 66.67 per cent. Average level of personal satisfaction 
is mostly found among educated women by 45.45 per cent and high level of personal satisfaction is also found among educated women by 98.45 per cent. Such differences between personal satisfaction and education is found insignificant ( $\mathrm{p}$ value $>0.05$ ) with $\chi^{2}$ value of 22.10 at 4 degree of freedom. Thus, low level of personal satisfaction is found among illiterate women and literate women; and high level of personal satisfaction is found among educated women.

Average level of overall life satisfaction is found among illiterate and literate women by 34.37 per cent; where as high level of overall life satisfaction is found among educated women by 77.27 per cent. Such differences between overall life satisfaction and education is found highly significant ( $\mathrm{p}$-value $<0.01$ ) with $\chi^{2}$ value of 23.07 at 2 degree of freedom. Sousa and Lubomirsky (2000) have found a small correlation between education and life satisfaction. However, the correlation appears to disappear when income and occupation are statistically controlled. That is, the relationship between education and life sat- isfaction is probably due to the fact that higher levels of education are associated with higher incomes. Education also appears to be more highly related to life satisfaction for individuals with lower incomes and in poor nations. Perhaps poorer persons obtain greater satisfaction from education because the achievement surpasses their expectations of what is attainable. For example, poor women in some cultures have little access to education, so when they do gain access, they may value and appreciate the experience more than those who perceive access to education as universal and easily available. Education may also provide access to greater occupational and income opportunities, which may additionally, influence life satisfaction

\section{Overall Life Satisfaction among Women}

Table 3 shows that there is not much difference in the mean scores of overall life satisfaction among women at low and middle age group, comprising 133.54 and 133.61 mean scores re-

Table 2: Life satisfaction among women as per their education $\quad(n=120)$

\begin{tabular}{|c|c|c|c|c|c|c|c|c|c|}
\hline \multirow[t]{3}{*}{ Life Satisfaction } & \multicolumn{8}{|c|}{ Education } & \multirow{3}{*}{$\chi^{2}$ value } \\
\hline & \multicolumn{2}{|c|}{ Illiterate } & \multicolumn{2}{|c|}{ Literate } & \multicolumn{2}{|c|}{ Educated } & \multirow[t]{2}{*}{ Total } & \multirow[t]{2}{*}{$\%$} & \\
\hline & $N$ & $\%$ & $N$ & $\%$ & $N$ & $\%$ & & & \\
\hline \multicolumn{10}{|l|}{ Career Satisfaction } \\
\hline Low & 3 & 75.00 & 1 & 25.00 & - & - & 4 & 100.00 & \multirow{4}{*}{$38.29_{4}^{* * *}$} \\
\hline Average & 13 & 22.41 & 19 & 32.76 & 26 & 44.83 & 58 & 100.00 & \\
\hline High & 2 & 3.45 & 4 & 6.90 & 52 & 89.66 & 58 & 100.00 & \\
\hline Total & 18 & 15.00 & 24 & 20.00 & 78 & 65.00 & 120 & 100.00 & \\
\hline \multicolumn{10}{|l|}{ Social Satisfaction } \\
\hline Low & 2 & 40.00 & 2 & 40.00 & 1 & 20.00 & 5 & 100.00 & \multirow{4}{*}{$21.47_{4}^{* * *}$} \\
\hline Average & 10 & 28.57 & $1 \overline{1}$ & 31.43 & 14 & 40.00 & 35 & 100.00 & \\
\hline High & 6 & 7.50 & 11 & 13.75 & 63 & 78.75 & 80 & 100.00 & \\
\hline Total & 18 & 15.00 & 24 & 20.00 & 78 & 65.00 & 120 & 100.00 & \\
\hline \multicolumn{10}{|c|}{ Familial Satisfaction } \\
\hline Low & 2 & 50.00 & - & - & 2 & 50.00 & 4 & 100.00 & \multirow{4}{*}{$11.13_{4}^{* * *}$} \\
\hline Average & 9 & 25.00 & 9 & 25.00 & 18 & 50.00 & 36 & 100.00 & \\
\hline .High & 7 & 8.75 & 15 & 18.75 & 58 & 72.50 & 80 & 100.00 & \\
\hline Total & 18 & 15.00 & 24 & 20.00 & 78 & 65.00 & 120 & 100.00 & \\
\hline \multicolumn{10}{|c|}{ Personal Satisfaction } \\
\hline Low & 2 & 66.67 & 1 & 33.33 & - & - & 3 & 100.00 & \multirow{4}{*}{$22.10_{4}^{* * *}$} \\
\hline Average & 11 & 25.00 & 13 & 29.55 & 20 & 45.45 & 44 & 100.00 & \\
\hline High & 5 & 6.85 & 10 & 13.70 & 58 & 79.45 & 73 & 100.00 & \\
\hline Total & 18 & 15.00 & 24 & 20.00 & 78 & 65.00 & 120 & 100.00 & \\
\hline \multicolumn{10}{|c|}{ Overall Satisfaction } \\
\hline Low & & & & & & & & & \multirow{4}{*}{$23.07_{2}^{*}$} \\
\hline Average & 11 & 34.37 & 11 & 34.37 & 10 & 31.25 & 32 & 100.00 & \\
\hline High & 7 & 7.95 & 13 & 14.77 & 68 & 77.27 & 88 & 100.00 & \\
\hline Total & 18 & 15.00 & 24 & 20.00 & 78 & 65.00 & 120 & 100.00 & \\
\hline
\end{tabular}


spectively. How ever, there is a slight decrease in the mean score of overall life satisfaction among women at high age group, i.e. 131.24 mean score. The standard deviation on mean scores of overall life satisfaction among women at low, middle and high age group is found $12.43,12.63$ and 18.34 respectively. Such differences between age of women and overall life satisfaction among women is found insignificant ( $\mathrm{p}$-value $>0.05$ ) with f-value of 0.33 at 2 degree of freedom. Thus, women observes average level of satisfaction at all age levels.

It is found that there is not much difference in the mean scores of overall life satisfaction among literate and educated women, comprising 124.75 and 138.23 mean scores respectively. However, there is slight decrease in the mean score of overall life satisfaction among illiterate women i.e. 120.39 mean score. The standard deviation on mean scores of overall life satisfaction among illiterate, literate and educated women is found $11.79,12.14$ and 12.79 respectively. Such differences between education of women and overall life satisfaction is found highly significant ( $\mathrm{p}-$ value $<0.01$ ) with f-value of 21.2 at 2 degree of freedom.

It is studied that there is not much difference in the mean scores of overall life satisfaction among working an non-working women comprising 139.80 and 125.6 mean scores. The standard deviation on mean scores of overall life satisfaction among working and non-working women is found 13.65 and 11.75 respectively. Such differences between occupation of women and overall life satisfaction among women is found highly significant (p-value $<0.01$ ) with f-value 18.31 at 1 degree of freedom.

It is observed that there is not much difference in mean score of overall life satisfaction

Table 3: Over all life satisfaction among women $(n=120)$

\begin{tabular}{|c|c|c|c|c|c|}
\hline Variable & Mean & Sample & S.D. & $f$-value & Level of significance \\
\hline \multicolumn{6}{|l|}{ Age } \\
\hline Low & 133.54 & 37 & 12.43 & \multirow{3}{*}{$0.33_{2}$} & \multirow{3}{*}{$<0.05$} \\
\hline Middle & 133.61 & 46 & 12.63 & & \\
\hline High & 131.24 & 37 & 18.43 & & \\
\hline \multicolumn{6}{|l|}{ Education } \\
\hline Illiterate & 120.39 & 18 & 11.79 & \multirow{3}{*}{$21.12_{2}$} & \multirow{3}{*}{$<0.01$} \\
\hline Literate & 124.75 & 24 & 12.14 & & \\
\hline Educated & 138.23 & 78 & 12.79 & & \\
\hline \multicolumn{6}{|l|}{ Occupation } \\
\hline Working & 139.80 & 60 & 13.65 & \multirow{3}{*}{$18.31_{1}$} & \multirow[b]{2}{*}{$<0.01$} \\
\hline Non-working & 125.92 & 60 & 11.75 & & \\
\hline \multicolumn{5}{|l|}{ Personal Income } & \\
\hline Nil & 125.92 & 60 & 11.80 & \multirow{4}{*}{$14.07_{3}$} & \multirow{4}{*}{$<0.01$} \\
\hline Low & 133.50 & 6 & 17.72 & & \\
\hline Middle & 136.71 & 24 & 13.70 & & \\
\hline High & 143.53 & 30 & 12.05 & & \\
\hline \multicolumn{6}{|l|}{ Family Income } \\
\hline Low & 124.60 & 45 & 16.96 & \multirow{3}{*}{$5.33_{2}$} & \multirow{3}{*}{$<0.01$} \\
\hline Middle & 125.67 & 24 & 12.56 & & \\
\hline High & 135.21 & 91 & 14.19 & & \\
\hline \multicolumn{6}{|l|}{ Marital Status } \\
\hline Unmarried & 133.77 & 48 & 12.91 & \multirow{5}{*}{$1.45_{4}$} & \\
\hline Married & 133.06 & 65 & 15.69 & & \\
\hline Divorced & 133.00 & 1 & 0.00 & & \\
\hline Separated & 146.00 & 1 & 0.00 & & \\
\hline Widow & 118.80 & 5 & 0.76 & & \\
\hline \multicolumn{6}{|l|}{ Type of Family } \\
\hline Joint & 129.68 & 57 & 13.44 & \multirow{3}{*}{$5.40_{1}$} & \multirow[t]{2}{*}{$<0.05$} \\
\hline Nuclear & 135.73 & 63 & 14.91 & & \\
\hline \multicolumn{5}{|l|}{ Dwelling } & \\
\hline Rural & 130.08 & 59 & 14.76 & \multirow{2}{*}{$4.37_{1}$} & \multirow[t]{2}{*}{$<0.05$} \\
\hline Urban & 135.54 & 61 & 13.82 & & \\
\hline
\end{tabular}

S.D denotes Standard deviation

Degree of freedom (d.f) in subscripts of f-value 
among women at low, middle and high personal income group, comprising 133.50, 136.71 and 143.53 mean scores respectively. However, there is slight decrease in the mean score of overall life satisfaction among women with no personal income i.e. 125.92 mean score. The standard deviation on mean scores of overall life satisfaction among women of no, low, middle and high personal income group is found 11.80, 17.72, 13.70 and 12.05 respectively. Such difference between personal income of women and overall life satisfaction among women is found highly significant (p-value <0.01) with f-value 14.07 at 3 degree of freedom.

It is observed that there is not much difference in the mean score of overall life satisfaction among women belonging to middle and high level of family income, comprising 125.67 and 135.21 mean score respectively. However, there is a slight decrease in the mean score of overall life satisfaction among women belonging to family with low income i.e. 124.60. The standard deviation on mean scores of overall life satisfaction among women at low, middle and high family income is $16.96,12.56$ and 14.19 respectively. Such differences between family income and overall life satisfaction is found highly significant with ( $p$-value $<0.01$ ) with f-value 5.33 at 2 degree of freedom.

It is found that there is not much difference in the mean score of overall life satisfaction among unmarried, married and divorced women, comprising $133.77,133.06$ and 133.00 respectively. However, there is a slight decrease in the mean score of overall life satisfaction among separated and widow women. The standard deviation on mean scores of overall life satisfaction among unmarried, married, divorced, separated and widow women are found 12.91, 15.69,0.00, 0.00 and 0.76 . Such difference between marital status of women and overall life satisfaction among women is found insignificant (p-value $>0.05$ ) with $\mathrm{f}$ value 1.45 at 4 degree of freedom.
It is observed that there is not much difference in the mean scores of overall life satisfaction among women belonging to joint and nuclear families comprising 129.68 and 135.73 mean scores respectively. The standard deviation on mean scores of overall life satisfaction among women belonging to joint and nuclear families are found 129.6 and 135.73 respectively. Such differences between type of family and overall life satisfaction among women is found insignificant ( $p$-value $>0.05$ ) with $\mathrm{f}$-value 1.45 at 1 degree of freedom.

It is found that there is not much difference in the mean scores of overall life satisfaction among rural and urban women, comprising 130.08 and 135.54 mean score respectively. The standard deviation on mean scores of overall life satisfaction among rural and urban women is found 14.76 and 13.82 respectively. Such differences between dwelling of women and overall life satisfaction are found significant ( $\mathrm{p}$-value $<0.05$ ) with f-value 4.37 at 1 degree of freedom. Alarape and Okurame (2001) examined menopausal status, timing of menopause and their influence on experience of depression and like satisfaction among 188 working women. Results of the study revealed that currently menopausal women experienced a significantly higher level of depression and a lower level of life satisfaction than non-menopausal and post menopausal women. There was a significant negative relationship between depression and life satisfaction among menopausal women. Diener and Fujita (1995) found that social resources are predictive of life satisfaction for both men and women, but they are more predictive of life satisfaction for women. Perhaps 18 women's roles as the conservators of contact with friends and family, both a blessing and a burden, lead to their relatively greater reliance on social support. By contrast, factors that may be more relevant to men's personal goals, such as athleticism, influential connections, and authority, were found to be related to life satisfaction for men.

Table 4: Correlation of life satisfaction among women on age and income $(n=120)$

\begin{tabular}{lccccc}
\hline & \multicolumn{4}{c}{ Dimensions } \\
\cline { 2 - 5 } & $r_{1}$ & $r_{2}$ & $r_{3}$ & $r_{4}$ & $r_{5}$ \\
\hline Age & -0.12 & 0.03 & 0.01 & 0.07 & 0.04 \\
Personal Income & 0.38 & 0.30 & 0.18 & 0.32 & 0.43 \\
Family Income & 0.28 & 0.19 & 0.19 & 0.33 & 0.40 \\
& Career & Social & Familial & Personal & Overall \\
& Satisfaction & Satisfaction & Satisfaction & Satisfaction & Satisfaction \\
\hline
\end{tabular}




\section{Correlation of Life Satisfaction on Age and Income}

Table 4 shows correlation of life satisfaction among women with age, personal income and family income. It is found that with an increase in age, the satisfaction in women's career decreases by 12 per cent; where as, career satisfaction increases with an increase in family income by 38 per cent. Similarly, with the increase in family income, career satisfaction also increases by 28 per cent. On the contrary, numerous studies have provided evidence that, contrary to common expectations, life satisfaction does not decline with age. For example, in a cross-cultural study conducted in 40 different nations and with nearly 6,000 participants, Ed Diener and Eunkook Suh (1998) found that life satisfaction generally remained stable throughout the life span, showing just a slight increasing trend between the ages of 20 and 80 years. It is also found from table 4 that with an increase in age, the women's social satisfaction decreases by 3 per cent, with an increase in personal income, women's social satisfaction increases by 30 per cent and with an increase in family income, social satisfaction of women increases by 19 per cent. It is observed that with an increase in age, the women's family satisfaction remains stable, with an increase in personal income, women's family satisfaction increases by 18 per cent and with an increase in family income, women's family satisfaction increases by 19 per cent. It is studied that with an increase in age, personal satisfaction of women decreases by 17 per cent, with an increase in personal income, personal satisfaction of women increases by 32 per cent and with an increase in family income, personal satisfaction increases by 33 per cent. It is seen that with an increase in age, the overall life satisfaction decreases by 40 per cent, with an increase in personal income, the overall life satisfaction increases by 43 per cent and with an increase in family income, the overall life satisfaction of women increases by 40 per cent. Sousa and Lyubomirsky (2000) found that significant correlations between life satisfaction and wealth, rises in people's incomes do not necessarily coincide with related increases in life satisfaction. For example, Americans' levels of life satisfaction before and after World War II did not increase despite significant growth in income during this time period. Several explanations have been offered to account for these re- sults. Perhaps once a certain level of wealth is obtained, life satisfaction is no longer anchored to increases in wealth and in material goods. In addition, social comparison may account for this effect - that is, comparing oneself with others as income and wealth increase may produce corresponding increases in expectations such that levels of satisfaction remain stable for women.

\section{CONCLUSION}

Average level of life satisfaction is found among women at high level of age group. Average level of social satisfaction is also found among women at high age group; whereas, high level of social satisfaction is found among women at average level of age group. High level of familial satisfaction is found among women at average level of age group. Low level of personal satisfaction is found among women at high level of age group; whereas, high level of personal satisfaction is found among women at average level of age group. Average level of life satisfaction is found among illiterate and literate women; whereas, high level of life satisfaction is found among educated women. Low level of career satisfaction is found among illiterate women; average level of career satisfaction is found among literate women, high level of career satisfaction is found among educated women. Low level of social satisfaction is found among literate and illiterate women and high level of social satisfaction is found among educated women. Moreover, low level of familial satisfaction is found among illiterate women; average level of familial satisfaction is found among literate women and high level of familial satisfaction is found among educated women. Low level of personal satisfaction is found among illiterate women and literate women; whereas, high level of personal satisfaction is found among educated women. The study is concluded by the fact that women observes average level of life satisfaction at all age levels and it is seen that with an increase in age, the over all life satisfaction decreases, with an increase in personal income, the over all life satisfaction increases and with an increase in family income, the over all life satisfaction of women also increases.

\section{REFERENCES}

Bettencourt A, Molix L 2003. Satisfaction with Health Care and Community Esteem among Rural Women. 
Journal of Analysis of Social Issues and Public Policy, 3(1): 1-14.

Beutell N 2006. Life Satisfaction, a Sloan Network Encyclopaedia Entry. Journal of Sloan Work and Family, 2(3): 1125-1127.

Borg $\mathrm{CH}$, Blomquist K 2006. Life satisfaction among older people $(65+)$ With Reduced Self-care Capacity: The Relationship to Social, Health and Financial Aspects. Journal of Clinical Nursing, 15: 607-618.

Chpperfield JG, Havens B 2001. Gender Differences in the Relationships between Marital Status Transitions and Life Satisfaction in Later Life. Journal of Marriage and the Family, 12 (3): 176-186.

Diener C, Fujita F 1995. A Study on Life Satisfaction. In: L Sousa, S Lyubomirsky. Life Satisfaction. New Jersey, Prentice Hall, pp. 56-89.

George LK, Okum MA, Landerman R.1979. Age as a Moderator of the Determinants of Life Satisfaction. Journal of Psychology of Women, Quarterly 3(3): 241-247.

Kousha M, Moheen N 2004. Predictors of Life Satisfaction among Urban Iranian Women: An
Exploratory Analysis. Journal of Social Indicators Research, 40(3): 320-357.

Rambur B, Mcintosh B, Val M, Palumbo S, Reinier K 2005. Education as a Determinant of Career Retention and Job Satisfaction among Registered Nurses. Journal of Nursing Scholarship, 37(2): 185192.

Saundra HS, Hughey AW 2003. African American Women at Mid life: The Relationship between Spirituality and life Satisfaction. Journal of African American Women, 18(2): 133-147.

Shichman S, Cooper E 2004. Life Satisfaction and Sexrole Concept. Journal of Sex-Role, 11: 227-240.

Singh P, Josephy G 1971. Life Satisfaction Scale. Luckhnow: National Psychological Corporation,

Sousa L, Lyubomirsky S 2000. Life Satisfaction. In: J Wore (Ed.): Encyclopaedia of Women and Gender. Sex Similarities and Differences and the Impact of Society on Gender. New Jersey, Prentice Hall, pp. 667-676.

Young W .2006. Social Support and Life Satisfaction. International Journal of Psychosocial Rehabilitation, 10(2): 155-164. 